\title{
Effects of lanreotide Autogel primary therapy on symptoms and quality-of-life in acromegaly: data from the PRIMARYS study
}

\author{
Philippe J. Caron ${ }^{1} \cdot$ John S. Bevan ${ }^{2} \cdot$ Stephan Petersenn $^{3} \cdot$ Aude Houchard $^{4}$ • \\ Caroline Sert $^{4} \cdot$ Susan M. Webb ${ }^{5,6} \cdot$ The PRIMARYS Investigators Group
}

Published online: 24 November 2015

(C) The Author(s) 2015. This article is published with open access at Springerlink.com

\begin{abstract}
Purpose To evaluate the effects of lanreotide Autogel on patient-reported outcomes and association with biochemical control, using PRIMARYS data.

Methods PRIMARYS was a 1-year, open-label study of lanreotide Autogel (Depot in USA) $120 \mathrm{mg}$ every 4 weeks in 90 treatment-naïve patients with acromegaly. Symptoms were assessed using Patient-assessed Acromegaly Symptom Questionnaire (PASQ) and health-related quality of life (HRQoL) using the AcroQoL questionnaire. Correlations between PASQ and AcroQoL scores, and between PASQ/AcroQoL and growth hormone (GH)/insulin-like growth factor-1 (IGF-1) levels were also evaluated (post hoc).
\end{abstract}

Additional investigators are listed in the "Appendix".

Electronic supplementary material The online version of this article (doi:10.1007/s11102-015-0693-y) contains supplementary material, which is available to authorized users.

Philippe J. Caron

caron.p@chu-toulouse.fr

1 Department of Endocrinology and Metabolic Diseases, Centre Hospitalier Universitaire Larrey, Toulouse, France

2 Department of Endocrinology, Aberdeen Royal Infirmary, Aberdeen, UK

3 ENDOC Center for Endocrine Tumors, Hamburg, Germany

4 Ipsen, Boulogne-Billancourt, France

5 Departments of Endocrinology/Medicine, Sant Pau Biomedical Research Institute, Hospital de Sant Pau, Universitat Autònoma de Barcelona, Barcelona, Spain

6 Center for Biomedical Network Research on Rare Diseases (CIBERER Unit 747), ISCIII, Barcelona, Spain
Results Acromegaly symptoms and HRQoL significantly improved from week 12 to week 48, with modest correlations at week 48 between PASQ total score $(\mathrm{R}=-0.55$, $p<0.0001)$ and AcroQoL global and physical scores $(\mathrm{R}=-0.67, p<0.0001)$. Approximately $60 \%$ of patients achieved a minimal important difference (MID; improvement $>50 \%$ of baseline standard deviation) in PASQ total score and $>40 \%$ achieved a MID in AcroQoL global score (post hoc). Changes in PASQ scores were similar in biochemically controlled (GH levels $\leq 2.5 \mu \mathrm{g} / \mathrm{L}$ and normal IGF-1 levels) and uncontrolled groups, while changes in global and psychological AcroQoL scores were greater in the controlled group. There was no correlation between changes in PASQ or AcroQoL scores and changes in $\mathrm{GH}$ or IGF-1 levels.

Conclusions Primary treatment with lanreotide Autogel over 1 year was associated with rapid and sustained improvements in clinical signs and symptoms and HRQoL in patients with acromegaly. Improvements in HRQoL, but not symptoms, were greater in those achieving biochemical control (ClinicalTrials.gov: NCT00690898; EudraCT: 2007-000155-34).

Keywords Acromegaly - Lanreotide Autogel - Quality of life $\cdot$ Symptoms

\section{Introduction}

Acromegaly is a multisystem disease, characterized by somatic overgrowth, multiple comorbidities (including diabetes and cardiovascular disorders), premature mortality, and physical disfigurement $[1,2]$. Perhaps not surprisingly, acromegaly is associated with psychological issues such as mood swings, impaired self-esteem, and 
disruptions in interpersonal relationships [2]. Furthermore, studies have shown that patients with acromegaly have impaired health-related quality of life (HRQoL), measured using both generic and disease-specific (AcroQoL) questionnaires [3, 4].

Treatment options for acromegaly include surgery, drug treatment, and radiotherapy. Goals of treatment are amelioration of clinical signs and symptoms, reduction of morbidity and mortality, and control of GH and IGF-1 hypersecretion and tumor growth $[1,5,6]$. The somatostatin analogs (SSAs), which include lanreotide Autogel (Depot in the USA), are largely recognized for their role in patients whose disease persists despite surgical intervention $[1,5,6]$. In addition, a number of guidelines on the management of acromegaly advocate the first-line use of longacting SSAs in those who cannot be cured using surgery or who are poor surgical candidates $[1,5,6]$. SSAs have been shown to improve acromegaly symptoms and limit $\mathrm{GH} /$ IGF-1 hypersecretion and tumor growth [7-10]. There is also evidence that SSAs improve HRQoL in acromegaly [11-13].

PRIMARYS was a robust, 1-year study designed to evaluate the effect of primary treatment with lanreotide Autogel $120 \mathrm{mg}$ every 4 weeks in 90 treatment-naïve patients with acromegaly [7]. The results showed that clinically significant tumor shrinkage $(\geq 20 \%)$ was achieved in $63 \%$ of patients and there were early and sustained improvements in growth hormone $(\mathrm{GH})$ and insulin-like growth factor-1 (IGF-1) levels, acromegaly symptoms, and HRQoL [7]. Lanreotide Autogel was well tolerated, with no patients discontinuing treatment due to gastrointestinal intolerance. The patient population enrolled in PRIMARYS was particularly homogeneous: all patients were treatment naïve and all were treated first-line with the highest available dose of lanreotide Autogel from the outset (i.e. there was no dose titration) in order to achieve rapid efficacy. In view of this, the relatively large number of patients enrolled, and the long duration of follow-up, we conducted a more in-depth analysis to further investigate the effects of treatment on patient-reported outcomes.

\section{Methods}

The methods used for this trial (ClinicalTrials.gov: NCT00690898 and EudraCT: 2007-000155-34) have previously been described in detail [7].

\section{Patients}

The study included treatment-naïve men and women, aged 18-75 years, diagnosed with acromegaly, with mean GH levels $>1 \mu \mathrm{g} / \mathrm{L}$ and IGF-1 levels above the normal age- and sex-matched range. All patients had a GH-secreting macroadenoma (diameter $\geq 10 \mathrm{~mm}$ ) without visual field defects. Patients were excluded if they had: undergone or were likely to need pituitary surgery or radiotherapy; previously received treatment with a SSA, dopamine agonist, or $\mathrm{GH}$ receptor antagonist; prolactin co-secretion $>100 \mu \mathrm{g} /$ L; optic nerve disease or any visual abnormality that may have worsened during the trial; or a glomerular filtration rate $<30 \mathrm{~mL} / \mathrm{min} / 1.73 \mathrm{~m}^{2}$.

Patients could be withdrawn from the study if they had an insufficient IGF-1 response $(<10 \%$ reduction in IGF-1 at Week 24 or an inadequate response in the investigator's opinion), if there was suspicion of visual field deterioration, in the event of a post-baseline prolactin level $>100 \mu \mathrm{g} / \mathrm{L}$, or if there were any other safety concerns.

\section{Trial design and interventions}

This was an international, 48-week, open-label, single-arm phase $3 \mathrm{~b}$ trial, conducted in 27 specialist endocrine centers in nine countries (Belgium, Czech Republic, Finland, France, Germany, Italy, The Netherlands, Turkey, and the United Kingdom) between May 20, 2008 and February 13, 2012. Patients received twelve injections of lanreotide Autogel $120 \mathrm{mg}$ by deep subcutaneous injection every 28 days. Dose titration was not permitted.

All patients gave written informed consent to participate before the start of the trial, which was conducted in accordance with the Declaration of Helsinki, Good Clinical Practice guidelines, and all local regulatory requirements. Trial documentation was approved by institutional review boards before the start of the trial.

\section{Assessments and endpoints}

Trial visits were conducted at baseline (week 1) and at weeks 12, 24, and 48. GH and IGF-1 levels were measured at each trial visit, as described previously [7]. The primary endpoint (change from baseline in pituitary tumor volume at week 48) and all secondary endpoints of the trial have been reported previously; here we present further detailed analyses on changes in acromegaly symptoms and changes in HRQoL. Symptoms were assessed at each visit using the Patient-assessed Acromegaly Symptom Questionnaire (PASQ), which allows patients to rate five key symptoms (headache, excessive perspiration, fatigue, soft tissue swelling, arthralgia) on a 9-point scale ( 0 , no symptoms; 8 , severe incapacitating symptoms) [14]. The total PASQ score is the sum of the individual symptom scores (maximum $=40$ ). HRQoL was assessed at each visit using the AcroQoL questionnaire (except Finland and Turkey, where validated translations were not available). The AcroQoL 
questionnaire is a reliable, validated tool [3] that assesses global HRQoL, physical performance, and psychological wellbeing. The psychological wellbeing dimension is further divided into sub-dimensions for 'appearance' and 'personal relationships'. Scores were standardized from 0 to 100 , with higher scores in all cases representing better HRQoL.

\section{Statistical analyses}

Summary statistics were based on the intention-to-treat (ITT) population and calculated for PASQ and AcroQoL scores at baseline, weeks 12, 24, and 48, and last postbaseline value available (LVA), and for the change in scores from baseline at these timepoints. Post hoc analyses were conducted to determine the percentage of patients with minimally important differences (MIDs) in PASQ and AcroQoL scores, defined as a change (improvement) $>50 \%$ of the baseline standard deviation (SD) of each score [15]. Post hoc analyses were also conducted to evaluate the following correlations in the overall population: total PASQ score versus AcroQoL global, physical and psychological dimension scores (Pearson correlation); individual PASQ symptom scores versus AcroQoL global, physical and psychological dimension scores (Kendall correlation); total PASQ score versus IGF-1 and GH levels, and AcroQoL global and subscale scores versus IGF-1 and GH levels. In all cases, correlations were conducted for absolute scores at week 48 and for changes in scores from baseline to week 48 . Finally, post hoc analyses were conducted to evaluate baseline characteristics, total PASQ score, and global and physical AcroQoL dimension scores in patients with and without biochemical control, defined as GH levels $\leq 2.5 \mu \mathrm{g} / \mathrm{L}$ and normal IGF-1 levels, at LVA.

\section{Results}

\section{Patient disposition and baseline characteristics}

Ninety patients received treatment and 89 were included in the ITT population; 26 patients $(29 \%)$ withdrew before week 48 and 64 patients $(71 \%)$ completed the trial. The most common reason for withdrawal was insufficient IGF1 response as per protocol at week $12(\mathrm{n}=18)$, followed by consent withdrawn $(\mathrm{n}=4)$, adverse events $(\mathrm{n}=3)$, and other reasons $(\mathrm{n}=1)$. One patient in the ITT population did not have data available on biochemical control; for this reason, there were 88 patients in the overall population in the current analyses. Of these, all completed the PASQ at baseline and 83 completed the AcroQoL questionnaire.

Baseline demography and clinical characteristics are summarized in Table 1 for the overall population and for those with and without biochemical control, and in Supplementary Table S1 for the 18 patients who withdrew because of insufficient IGF-1 response. Patients with biochemical control $(\mathrm{GH} \leq 2.5 \mu \mathrm{g} / \mathrm{L}$ and IGF- $1<\mathrm{ULN})$ at LVA were significantly older at baseline than those in the uncontrolled group at LVA, and had significantly lower baseline IGF-1 levels (Table 1). Patients with biochemical control tended to be female ( 70 vs. $45 \%$ in the uncontrolled group) and tended to have lower median baseline tumor volumes (1339 vs. $1786 \mathrm{~mm}^{3}$ in the uncontrolled group). There were no statistically or clinically significant differences in baseline characteristics between the group who withdrew because of insufficient response and the ITT population excluding these 18 patients (Table 1).

\section{IGF-1, acromegaly symptoms, and HRQoL in the overall population}

As previously reported (7), mean IGF-1 levels were greatly reduced at week 12 versus baseline, and reductions were maintained until the end of the trial.

PASQ scores at baseline $(\mathrm{n}=88)$ and during treatment (week 12, $\mathrm{n}=87$; week $48, \mathrm{n}=62$ ) are shown in Table 1 and Fig. 1, and the percentage of patients with a MID in PASQ is shown in Supplementary Figure S1. The most troublesome symptoms at baseline were fatigue and soft tissue swelling, whereas headache was least troublesome (Table 1). The PASQ total score decreased significantly between baseline and week 12 (mean change, -7.1); this decrease was maintained at LVA (mean change, -7.6) (Fig. 1). Early and sustained reductions were also observed in each of the individual symptom scores. At LVA, greatest mean change was in excessive perspiration $(-1.9)$ and smallest mean change was in headache $(-0.9)$. Over half of patients experienced a MID in their PASQ total score at week $12(59 \%)$ and LVA (63\%). For the individual symptoms, excessive perspiration and soft tissue swelling showed greatest improvement, with MIDs in $51 \% / 51 \%$ (week 12/LVA) and $49 \% / 62 \%$ of patients, respectively, while the lowest MID rates were for headache with $26 \%$ / $30 \%$ (Figure S1).

AcroQoL scores at baseline $(\mathrm{n}=81-83)$ and during the study (week 12, $\mathrm{n}=81-82$; week $48, \mathrm{n}=57-59$ ) are shown in Table 1 and Fig. 2, and the percentage of patients with a MID during treatment is shown in Supplementary Figure S1. At baseline, the greatest impairment was for the psychological sub-dimension, appearance and the least impairment was for the psychological sub-dimension, personal relationships (Table 1). The improvement in the global AcroQoL score from baseline was significant at week 12 (mean change, 8.0) and at LVA (mean change, 7.9) (Fig. 2). During treatment, the greatest improvements in each of the dimension or sub-dimensions were seen 
Table 1 Baseline demography and disease characteristics in the overall population and according to achievement of biochemical control

\begin{tabular}{|c|c|c|c|}
\hline & Overall population $(\mathrm{n}=88)^{\mathrm{a}}$ & $\begin{array}{l}\text { Patients achieving biochemical } \\
\text { control }(\mathrm{n}=30)\end{array}$ & $\begin{array}{l}\text { Patients not achieving } \\
\text { biochemical control }(\mathrm{n}=58)\end{array}$ \\
\hline Age, years & $49.5(46.9,52.1)$ & $56.1(52.4,59.7)$ & $46.1(42.8,49.3)$ \\
\hline Female, $\mathrm{n}$ & 47 & 21 & 26 \\
\hline$\%(95 \% \mathrm{CI})$ & $53.4(42.5,64.1)$ & $70.0(50.6,85.3)$ & $44.8(31.7,58.5)$ \\
\hline BMI, $\mathrm{kg} / \mathrm{m}^{2}$ & $27.7(26.7,28.7)$ & $26.4(24.9,27.9)$ & $28.4(27.1,29.7)$ \\
\hline Time since acromegaly diagnosis, days & $121.1(84.6,157.6)$ & $147.0(44.8,249.3)$ & $107.3(87.1,127.5)$ \\
\hline \multicolumn{4}{|l|}{ Maximum tumor diameter, mm } \\
\hline Mean $(95 \% \mathrm{CI})$ & $18.9(17.4,20.4)$ & $17.3(15.6,19.1)$ & $19.8(17.7,21.9)$ \\
\hline Median (interquartile range) & $18.1(13.9,21.8)$ & $17.2(13.4,20.2)$ & $18.2(14.2,23.0)$ \\
\hline \multicolumn{4}{|l|}{ Maximum tumor volume, $\mathrm{mm}^{3}$} \\
\hline Mean $(95 \% \mathrm{CI})$ & $2731(2033,3428)$ & $1822(1211,2433)$ & $3201(2199,4203)$ \\
\hline Median (interquartile range) & $1653(866,3370)$ & $1339(811,2325)$ & $1786(958,4404)$ \\
\hline \multicolumn{4}{|l|}{ GH level, $\mu \mathrm{g} / \mathrm{L}$} \\
\hline Mean $(95 \% \mathrm{CI})$ & $15.2(11.2,19.2)$ & $13.0(6.6,19.3)$ & $16.3(11.1,21.6)$ \\
\hline Median (interquartile range) & $8.6(3.8,16.8)$ & $6.4(2.9,14.9)$ & $9.7(4.6,17.3)$ \\
\hline \multicolumn{4}{|l|}{ IGF-1 level, $\mu \mathrm{g} / \mathrm{L}$} \\
\hline Mean $(95 \% \mathrm{CI})$ & $796(735,857)$ & $665(563,767)$ & $863(792,935)$ \\
\hline Median (interquartile range) & $778(594,973)$ & $630(472,794)$ & $805(674,1010)$ \\
\hline IGF-1 levels, \% of ULN & $285(260.6,309.3)$ & $249(211.2,286.7)$ & $304(272.6,334.6)$ \\
\hline \multicolumn{4}{|l|}{ PASQ scores, mean $(95 \% \mathrm{CI})$} \\
\hline Total & $19.4(17.7,21.1)$ & $19.8(16.9,22.7)$ & $19.2(17.0,21.5)$ \\
\hline Headache & $2.8(2.2,3.3)$ & $2.0(1.2,2.9)$ & $3.1(2.5,3.8)$ \\
\hline Excessive perspiration & $4.0(3.4,4.5)$ & $4.1(3.2,5.1)$ & $3.9(3.2,4.6)$ \\
\hline Fatigue & $4.5(4.0,5.0)$ & $5.0(4.1,5.9)$ & $4.3(3.7,4.9)$ \\
\hline Soft tissue swelling & $4.3(3.7,4.8)$ & $4.6(3.7,5.5)$ & $4.1(3.5,4.7)$ \\
\hline Arthralgia & $3.9(3.4,4.5)$ & $4.1(3.2,5.0)$ & $3.8(3.1,4.6)$ \\
\hline \multicolumn{4}{|l|}{ AcroQoL scores ${ }^{\mathrm{b}}$, mean $(95 \% \mathrm{CI})$} \\
\hline Global & $56.0(52.5,59.5)$ & $50.9(45.1,56.7)$ & $58.8(54.4,63.1)$ \\
\hline Physical & $54.6(50.4,58.8)$ & $52.2(44.6,59.7)$ & $55.9(50.7,61.1)$ \\
\hline Psychological & $56.9(53.1,60.6)$ & $50.2(44.5,56.0)$ & $60.5(55.7,65.2)$ \\
\hline Psychological (appearance) & $41.4(37.0,45.7)$ & $34.1(27.8,40.4)$ & $45.4(39.7,51.0)$ \\
\hline Psychological (personal relationships) & $71.7(67.6,75.7)$ & $65.1(58.0,72.2)$ & $75.0(70.1,79.8)$ \\
\hline
\end{tabular}

$C I$ confidence interval, $B M I$ body mass index, $I G F-1$ insulin-like growth factor-1, $G H$ growth hormone, $S D$ standard deviation, $U L N$ upper limit of normal

${ }^{\text {a }}$ Excludes one patient in the ITT population with no data available on biochemical control. Data are the mean (95\% CI) unless otherwise specified; italic cells indicate parameters with non-overlapping CIs for biochemical control and lack of biochemical control (i.e. statistically significant differences). Biochemical control defined as GH levels $\leq 2.5 \mu \mathrm{g} / \mathrm{L}$ and normal IGF-1 levels at last post-baseline value available

${ }^{\mathrm{b}} \mathrm{n}=83$ for overall population ( 29 for controlled, 54 for uncontrolled)

between baseline and week 12; these improvements continued (psychological dimension, appearance sub-dimension) or remained relatively stable (physical dimension, personal relationships sub-dimension) through to week 48. MID rates during treatment for the AcroQoL global score were $43 \%$ at week 12 and $42 \%$ at LVA, with appearance showing the greatest improvement (52\%/55\%), and personal relationships sub-dimension showing the least improvement (33\%/28\%) (Figure S1).

\section{Correlation analyses in the overall population}

For week-48 scores, there was a moderate correlation between the total PASQ and both global and physical AcroQoL scores $(\mathrm{R}=-0.55$ and $\mathrm{R}=-0.67$; both $p<0.0001$ ), but not psychological AcroQoL dimension scores $(\mathrm{R}=-0.27, p=0.0017$; Supplementary Table $\mathrm{S} 3)$. The correlations between the total PASQ score and AcroQoL domain scores were stronger than those between the 


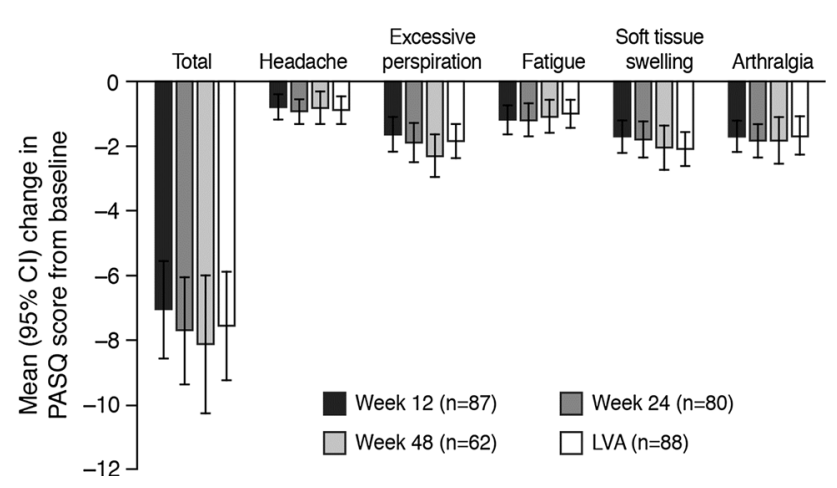

Fig. 1 Mean $(95 \% \mathrm{CI})$ change in PASQ scores during treatment with Lanreotide Autogel. Each symptom is assessed on a 9-point scale, total maximum score $=40$ (higher scores indicate worse symptoms); baseline scores are summarized in Table 1. Full data for this Figure are provided in Supplementary Table S2. CI confidence interval, $P A S Q$ patient-assessed acromegaly symptom questionnaire

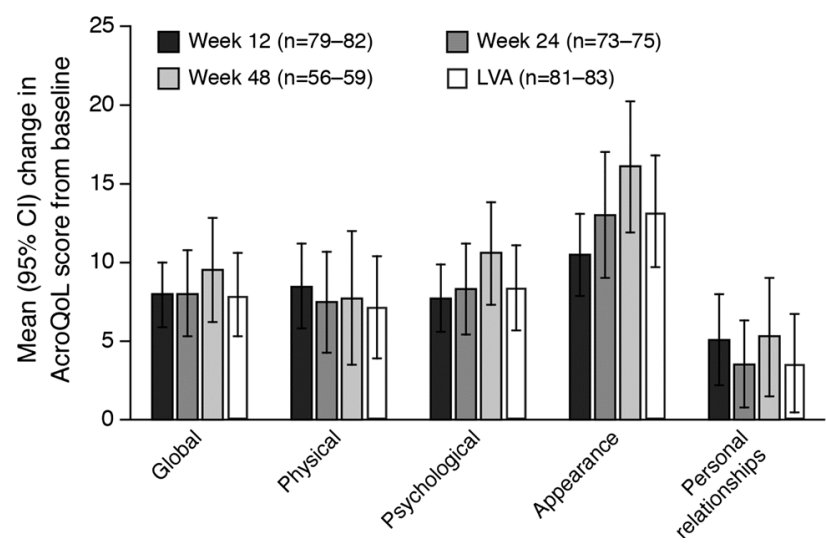

Fig. 2 Mean $(95 \% \mathrm{CI})$ change in AcroQoL scores during treatment with Lanreotide Autogel. Scores for each dimension/sub-dimension are standardized from 0 to 100 (higher scores = better HRQoL); baseline scores are summarized in Table 1. Full data for this Figure are provided in Supplementary Table S2. CI confidence interval, AcroQoL acromegaly quality of life questionnaire

individual PASQ symptom scores and the AcroQoL domain scores. For changes from baseline to week-48 scores, there were no correlations between PASQ total/individual symptom scores and AcroQoL domains. Finally, there were no correlations for week-48 scores or changes from baseline to week 48 for GH/IGF-1 levels and either PASQ or AcroQoL scores.

\section{Acromegaly symptoms and HRQoL in patients according to biochemical response}

At baseline, PASQ symptom scores were similar in the two groups (Table 1). In addition, there were no significant differences in the change in symptom scores from baseline to LVA between the biochemically controlled and the uncontrolled groups (Supplementary Table S4). There was no significant difference in baseline AcroQoL scores in the groups with and without subsequent biochemical control (Table 1). However, the mean [95\% CI] change in the global AcroQoL score at LVA was significantly higher in the controlled group (14.4 [9.8-19.0]) than in the uncontrolled subjects (4.4 [1.5-7.4]), as were the changes in the psychological dimension, and the appearance and personal relationships sub-dimension scores (Fig. 3). Conversely, there was no significant difference between the controlled and uncontrolled groups for the physical AcroQoL score at LVA.

Changes in PASQ total and AcroQoL global scores in the 18 patients who withdrew because of insufficient IGF-1 response are summarized in Supplementary Figure S2. Compared with the ITT population excluding these 18 patients, there appeared to be smaller improvements in PASQ and AcroQoL scores, but between-group differences were not statistically significant.

\section{Discussion}

The results of the current analyses show that primary medical treatment of acromegaly with lanreotide Autogel $120 \mathrm{mg}$ is associated with early and sustained improvements in patient-reported symptoms and HRQoL. Improvements were noted across all symptoms evaluated (headache, excessive perspiration, fatigue, soft tissue swelling, and arthralgia) and approximately $60 \%$ of patients had a clinically significant improvement (MID) in their total symptom score at LVA. Similarly, improvements were noted across all HRQoL dimension and subdimension scores (physical, psychological, appearance, and personal relationships) and $>40 \%$ of patients had a clinically significant improvement in their global HRQoL score at LVA. Amongst the AcroQoL dimensions and sub-dimensions, the greatest proportion of patients had clinically significant improvements in the appearance sub-dimension. This sub-dimension also scored worst at baseline, so the greater effect of treatment may reflect a larger scope for improvement.

As reported previously [7], mean GH and IGF-1 levels were significantly reduced at week 12 versus baseline, and improvements were maintained until the end of the trial. Improvements in acromegaly symptoms were also greatest during the first 12 weeks. Interestingly, however, the total and individual symptom scores during the study did not differ in those who achieved biochemical control (GH $\leq 2.5 \mu \mathrm{g} / \mathrm{L}$ and normal IGF-1 levels), compared with those who did not. Furthermore, there were no correlations between symptom scores and GH or IGF-1 levels. These results suggest that there may be a dissociation between hormonal control and symptom improvement, possibly 


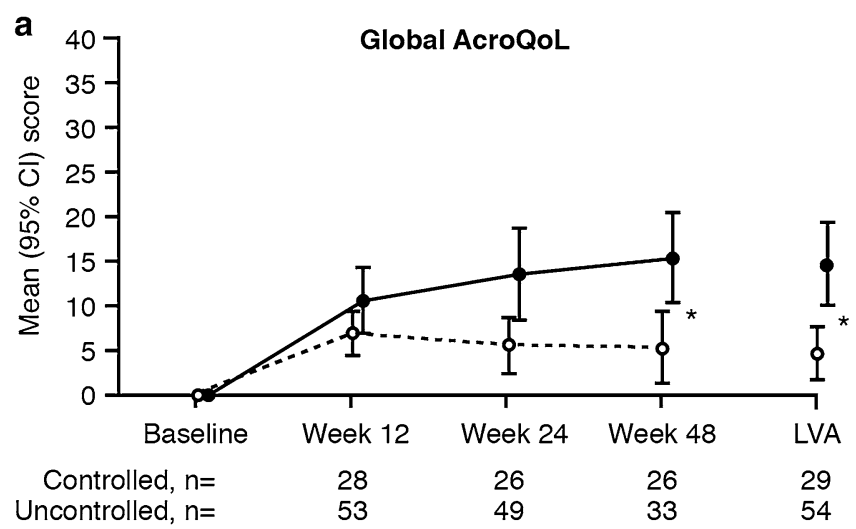

b

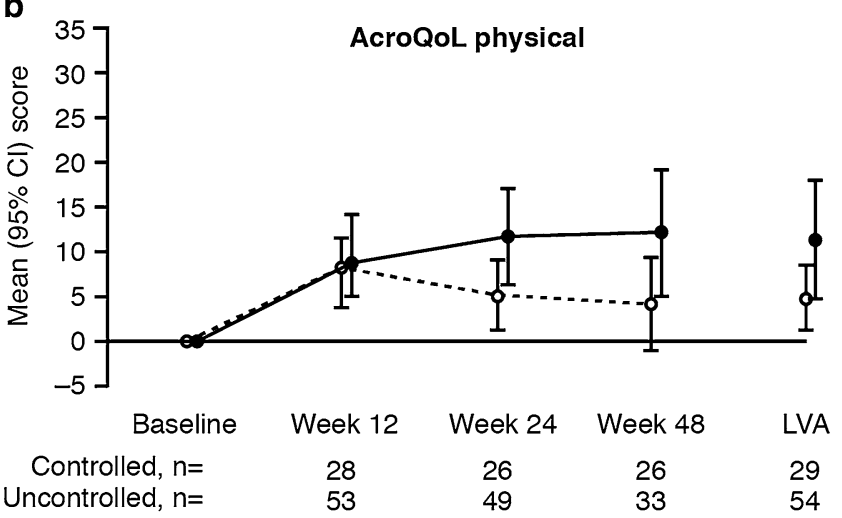

C

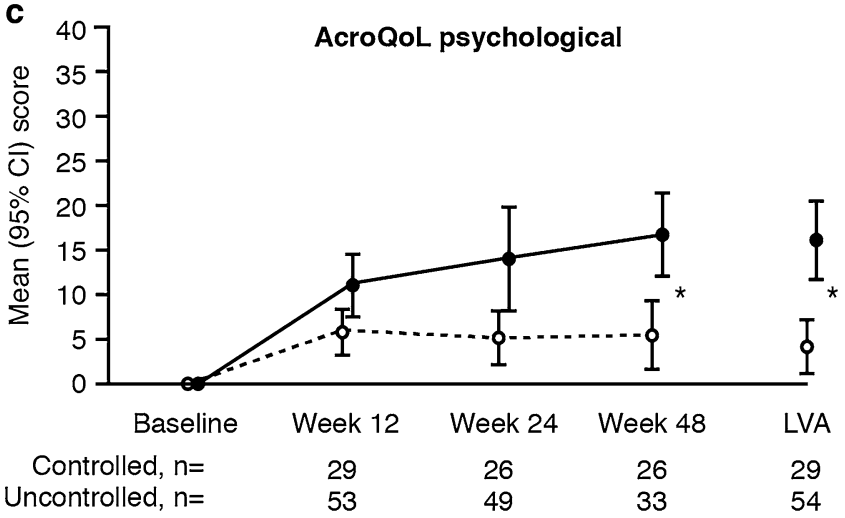

Fig. 3 Changes in AcroQoL scores for patients with and without biochemical control during treatment with Lanreotide Autogel. AcroQoL acromegaly quality of life questionnaire, $C I$ confidence

reflecting patients' long-term experience of the disease before diagnosis, the effect of comorbidities, or underlying differences in baseline characteristics between those with and without biochemical control (e.g. age and possibly gender). With regards to HRQoL, there was a modest correlation between the total PASQ and both global and physical AcroQoL scores. There were no correlations between any of these HRQoL scores and GH or IGF-1 levels, but improvements in the global and psychological AcroQoL scores were significantly greater in those who achieved biochemical control compared with those who did
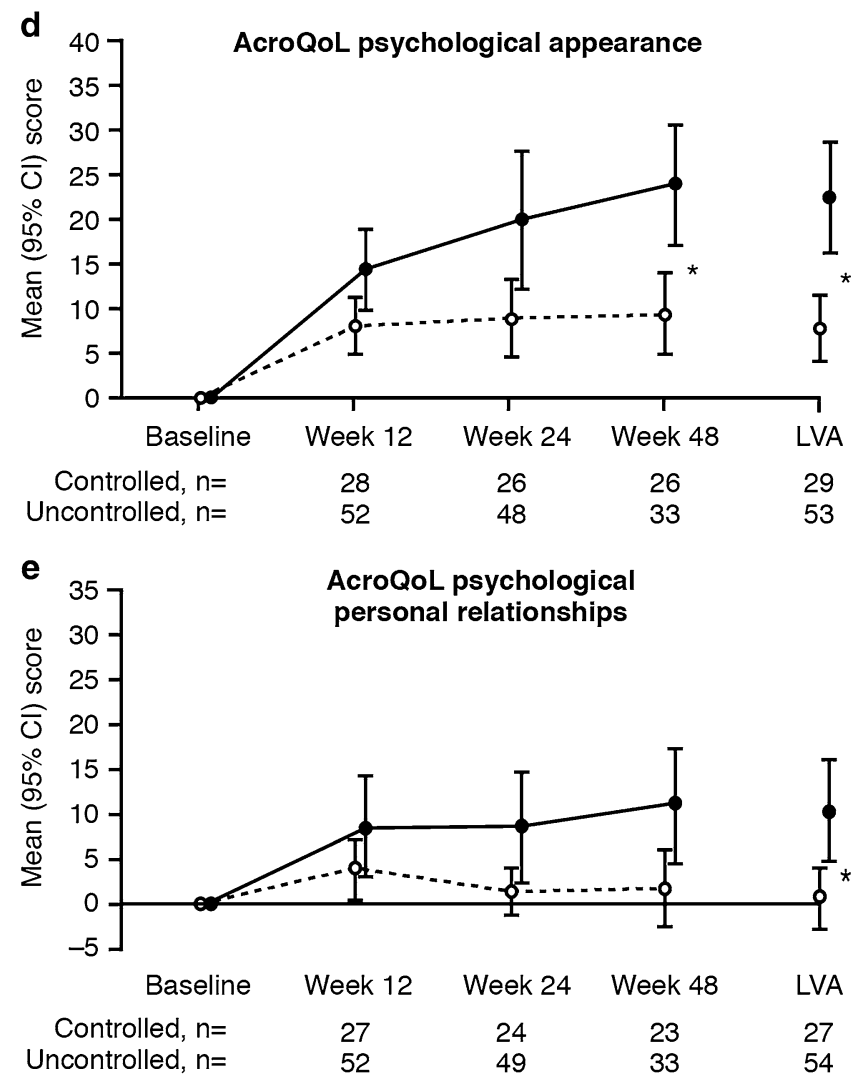

interval. Asterisks indicate non-overlapping CIs, i.e. statistically significant between-group differences. Baseline scores are summarized in Table 1

not. A number of previous studies have evaluated the association between HRQoL and biochemical control; the results are mixed, with some showing better HRQoL in those with biochemical control, and others showing no such association [16, 17]. Interestingly, in one study, IGF-1 control was associated with better scores on the AcroQoL appearance sub-dimension, but not for the global, physical or psychological dimensions [18]. In another study, administration of pegvisomant to patients biochemically controlled with a SSA resulted in an improvement in HRQoL despite no change in IGF-1 levels [14]. 
The relationship between biochemical control (as determined by circulating hormones) and HRQoL therefore remains to be determined, but it should be borne in mind that HRQoL can be affected by a number of factors associated with acromegaly and the treatment modality. These include cosmetic or orthopedic deformities or comorbidities, which may already be established in some patients, particularly in view of the time lag between symptom onset and diagnosis [16]. It has also been shown that illness perception affects HRQoL in those with acromegaly [19]. In addition, tissue sensitivity to GH and IGF-1 excess can vary [14], which may also explain the apparent disconnect between HRQoL and circulating levels of GH and IGF-1 in some studies. Finally, it should be borne in mind that the studies in which HRQoL and biochemical control have been assessed include heterogeneous populations in terms of treatments received (surgery, radiotherapy, medical treatment, or a combination of these) [14, 16-18], which could also impact on HRQoL. Indeed, one of the strengths of the current study was the homogeneity of the patient population, who were all treatment naïve.

Other studies have used the PASQ and AcroQoL to assess symptoms and HRQoL in those treated for acromegaly [9, 12, 20-23]. In the observational ACROSTUDY of the GH receptor antagonist, pegvisomant, only the PASQ score for excessive perspiration was significantly improved following 1 year's treatment; after 2 years, numbness and soft tissue swelling were significantly reduced [20]. HRQoL was assessed using AcroQoL in a recent randomized study comparing octreotide LAR and pasireotide LAR in 358 medical treatment-naïve patients; baseline scores (55.6 and 58.4) were similar to those in the current study (56.0). After 1 year, scores increased by 4.9 in the octreotide LAR group and 7.0 in the pasireotide group; the results in the current study (increase of 9.5) compare well with these [7]. Larger increases in the AcroQoL global score $(+17)$ were noted with octreotide LAR in an earlier observational study, but it included only 28 patients treated for 4 years, so the results are more difficult to compare [12].

One limitation of the current study was its open-label, uncontrolled design. However, this was felt to be justified because of the objective nature of the primary endpoint, tumor volume reduction [7]. Strengths of the study, particularly in the context of the patient-reported outcomes, include the relatively large size of the patient population, its homogeneity, and the long duration of follow-up. Many of the previously reported studies evaluating the effect of SSAs on HRQoL included fewer than 50 patients [12-14, 24-26]. Furthermore, unlike many of the other studies [11, 12, 14, 26], patients were treatment naïve, and as such, they represent an appropriate population for evaluating patient-reported outcomes and HRQoL in the earlier stages of treatment.
The results of the current study confirmed that medical treatment with lanreotide provided meaningful improvements not only in hormone levels, but also in clinical outcomes as evaluated by the PASQ and AcroQoL questionnaires. The relationship between biochemical and PASQ improvements was not clear, whereas the association between biochemical and AcroQoL improvements was more apparent. This divergence highlights the importance, wherever practicable, of using more than one appropriate questionnaire, in addition to biochemical measures, to fully evaluate clinical outcomes during medical treatment for acromegaly. Such an approach will offer different, but complementary, information on treatment response. In particular, it is most important to consider using a tool, such as AcroQoL, that assesses patients' subjective perceptions of the impact of disease on their daily HRQoL, as this outcome cannot always be reliably inferred from biochemical markers or objective symptom evaluation.

In conclusion, primary treatment with lanreotide Autogel $120 \mathrm{mg}$ every 4 weeks for 1 year was associated with early and sustained improvements in signs and symptoms and HRQoL in patients with acromegaly. Symptom improvement did not appear to depend exclusively on biochemical control. On the other hand, improvements in HRQoL may reflect improvements in clinical signs and symptoms in these patients as well as a decrease of GH/IGF-1 hypersecretion. These results highlight the importance of using appropriate questionnaires to fully evaluate clinical outcomes during medical treatment for acromegaly.

Acknowledgments The authors thank the patients, their families, and investigators who participated in this trial. We thank Watermeadow Medical for writing assistance (funded by Ipsen).

Author contribution P J Caron, J S Bevan, and S Petersenn were involved in: concept and design of the study; patient enrolment into the study; analysis and interpretation of the data; and drafting of the manuscript. S M Webb, A Houchard and C Sert were involved in: analysis and interpretation of the data; and drafting of the manuscript. All authors approved the final version to be published and agree to be accountable for all aspects of the work.

Sponsorship This study was sponsored by Ipsen.

\section{Compliance with ethical standards}

Conflict of interest P J Caron is a consultant and speaker for Ipsen and Novartis, and an advisory board member for Ipsen. J S Bevan is a consultant and study investigator for Ipsen, and an advisory board member for Novartis and ViroPharma. S Peterssen has received lecture fees and participated in advisory boards for Ipsen, Novartis, and Pfizer. S M Webb has received speaker fees from Ipsen and has been involved in some of their clinical trials. A Houchard and C Sert are employed by Ipsen.

Open Access This article is distributed under the terms of the Creative Commons Attribution 4.0 International License (http://crea tivecommons.org/licenses/by/4.0/), which permits unrestricted use, 
distribution, and reproduction in any medium, provided you give appropriate credit to the original author(s) and the source, provide a link to the Creative Commons license, and indicate if changes were made.

\section{Appendix}

\section{PRIMARYS Study Group}

\section{Belgium L. Van Gaal; Czech Republic J. Marek; Finland} P. Nuutila, M. Välimäki; France C. Ajzenberg, F. BorsonChazot, T. Brue, P. Caron, O. Chabre, P. Chanson, C. Cortet Rudelli, B. Delemer, J.-M. Kuhn, A. Tabarin; Germany K. Badenhoop, C. Berg, S. Petersenn, C. Schöfl, J. Schopohl; Italy S. Cannavò, A. Colao, L. De Marinis; the Netherlands A. Stades, A.J. van der Lely; Turkey P. Kadıoğlu; UK J.S. Bevan, D. Flanagan, P. Trainer.

\section{References}

1. Katznelson L, Laws ER Jr, Melmed S, Molitch ME, Murad MH, Utz A, Wass JA (2014) Acromegaly: an endocrine society clinical practice guideline. J Clin Endocrinol Metab 99:3933-3951

2. Pantanetti P, Sonino N, Arnaldi G, Boscaro M (2002) Self image and quality of life in acromegaly. Pituitary 5:17-19

3. Webb SM, Badia X, Surinach NL, Spanish AcroQol Study Group (2006) Validity and clinical applicability of the acromegaly quality of life questionnaire, AcroQoL: a 6-month prospective study. Eur J Endocrinol 155:269-277

4. Rowles SV, Prieto L, Badia X, Shalet SM, Webb SM, Trainer PJ (2005) Quality of life (QOL) in patients with acromegaly is severely impaired: use of a novel measure of QOL: acromegaly quality of life questionnaire. $\mathrm{J}$ Clin Endocrinol Metab 90:3337-3341

5. Giustina A, Chanson P, Kleinberg D, Bronstein MD, Clemmons DR, Klibanski A, van der Lely AJ, Strasburger CJ, Lamberts SW, Ho KK, Casanueva FF, Melmed S, Acromegaly Consensus Group (2014) Expert consensus document: a consensus on the medical treatment of acromegaly. Nat Rev Endocrinol 10:243-248

6. Katznelson L, Atkinson JL, Cook DM, Ezzat SZ, Hamrahian AH, Miller KK (2011) American Association of Clinical Endocrinologists medical guidelines for clinical practice for the diagnosis and treatment of acromegaly-2011 update. Endocr Pract 17(Suppl 4):1-44

7. Caron PJ, Bevan JS, Petersenn S, Flanagan D, Tabarin A, Prévost G, Maisonobe P, Clermont A (2014) Tumor shrinkage with lanreotide Autogel $120 \mathrm{mg}$ as primary therapy in acromegaly: results of a prospective multicenter clinical trial. J Clin Endocrinol Metab 99:1282-1290

8. Colao A, Auriemma RS, Rebora A, Galdiero M, Resmini E, Minuto F, Lombardi G, Pivonello R, Ferone D (2009) Significant tumour shrinkage after 12 months of lanreotide Autogel-120 mg treatment given first-line in acromegaly. Clin Endocrinol 71:237-245

9. Colao A, Bronstein MD, Freda P, Gu F, Shen CC, Gadelha M, Fleseriu M, van der Lely AJ, Farrall AJ, Hermosillo Reséndiz K, Ruffin M, Chen Y, Sheppard M (2014) Pasireotide versus octreotide in acromegaly: a head-to-head superiority study. J Clin Endocrinol Metab 99:791-799
10. Mercado M, Borges F, Bouterfa H, Chang TC, Chervin A, Farrall AJ, Patocs A, Petersenn S, Podoba J, Safari M, Wardlaw J (2007) A prospective, multicentre study to investigate the efficacy, safety and tolerability of octreotide L. Clin Endocrinol 66:859-868

11. Lombardi G, Minuto F, Tamburrano G, Ambrosio MR, Arnaldi G, Arosio M, Chiarini V, Cozzi R, Grottoli S, Mantero F, Bogazzi F, Terzolo M, Tita P, Boscani PF, Colao A (2009) Efficacy of the new long-acting formulation of lanreotide (lanreotide Autogel) in somatostatin analogue-naive patients with acromegaly. J Endocrinol Investig 32:202-209

12. Mangupli R, Camperos P, Webb SM (2014) Biochemical and quality of life responses to octreotide-LAR in acromegaly. Pituitary 17:495-499

13. Sonino N, Scarpa E, Paoletta A, Fallo F, Boscaro M (1999) Slowrelease lanreotide treatment in acromegaly: effects on quality of life. Psychother Psychosom 68:165-167

14. Neggers SJ, van Aken MO, de Herder WW, Feelders RA, Janssen JA, Badia X, Webb SM, van der Lely AJ (2008) Quality of life in acromegalic patients during long-term somatostatin analog treatment with and without pegvisomant. J Clin Endocrinol Metab 93:3853-3859

15. Norman GR, Sloan JA, Wyrwich KW (2003) Interpretation of changes in health-related quality of life: the remarkable universality of half a standard deviation. Med Care 41:582-592

16. Ben-Shlomo A, Sheppard MC, Stephens JM, Pulgar S, Melmed S (2011) Clinical, quality of life, and economic value of acromegaly disease control. Pituitary 14:284-294

17. Postma MR, Netea-Maier RT, van den Berg G, Homan J, Sluiter WJ, Wagenmakers MA, van den Bergh ACM, Wolffenbuttel BHR, Hermus ARMM, van Beek AP (2012) Quality of life is impaired in association with the need for prolonged postoperative therapy by somatostatin analogs in patients with acromegaly. Eur J Endocrinol 166:585-592

18. Matta MP, Couture E, Cazals L, Vezzosi D, Bennet A, Caron P (2008) Impaired quality of life of patients with acromegaly: control of GH/IGF-I excess improves psychological subscale appearance. Eur J Endocrinol 158:305-310

19. Tiemensma J, Kaptein AA, Pereira AM, Smit JW, Romijn JA, Biermasz NR (2011) Affected illness perceptions and the association with impaired quality of life in patients with long-term remission of acromegaly. J Clin Endocrinol Metab 96:3550-3558

20. Buchfelder M, Schlaffer S, Droste M, Mann K, Saller B, Brübach K, Stalla GK, Strasburger CJ (2009) The German ACROSTUDY: past and present. Eur J Endocrinol 161(Suppl 1):S3-S10

21. Milian M, Honegger J, Gerlach C, Psaras T (2013) Health-related quality of life and psychiatric symptoms improve effectively within a short time in patients surgically treated for pituitary tumors-a longitudinal study of 106 patients. Acta Neurochir 155:1637-1645

22. Sardella C, Lombardi M, Rossi G, Cosci C, Brogioni S, Scattina I, Webb SM, Gasperi M, Martino E, Bogazz IF (2013) Short- and long-term changes of quality of life in patients with acromegaly: results from a prospective study. J Endocrinol Investig 33:20-25

23. Sievers C, Brubach K, Saller B, Schneider HJ, Buchfelder M, Droste M, Mann K, Strasburger CJ, Stalla GK (2010) Change of symptoms and perceived health in acromegalic patients on pegvisomant therapy: a retrospective cohort study within the German Pegvisomant Observational Study (GPOS). Clin Endocrinol 73:89-94

24. Karaca Z, Tanriverdi F, Elbuken G, Cakir I, Donmez H, Selcuklu A, Durak AC, Dokmetas HS, Colak R, Unluhizarci K, Kelestimur F (2011) Comparison of primary octreotide-lar and surgical treatment in newly diagnosed patients with acromegaly. Clin 1 Endocrinol 75:678-684

25. Ruchala M, Stangierska I, Gurgul E, Stangierski A, Fajfer J, Sowinski J (2010) The effect of octreotide treatment on somatic 
and psychological symptoms of acromegaly. Neuro Endocrinol Lett 31:265-269

26. Schopohl J, Strasburger CJ, Caird D, Badenhoop K, Beuschlein F, Droste M, Plöckinger U, Petersenn S (2011) Efficacy and acceptability of lanreotide Autogel(R) $120 \mathrm{mg}$ at different dose intervals in patients with acromegaly previously treated with octreotide LAR. Exp Clin Endocrinol Diab 119:156-162 